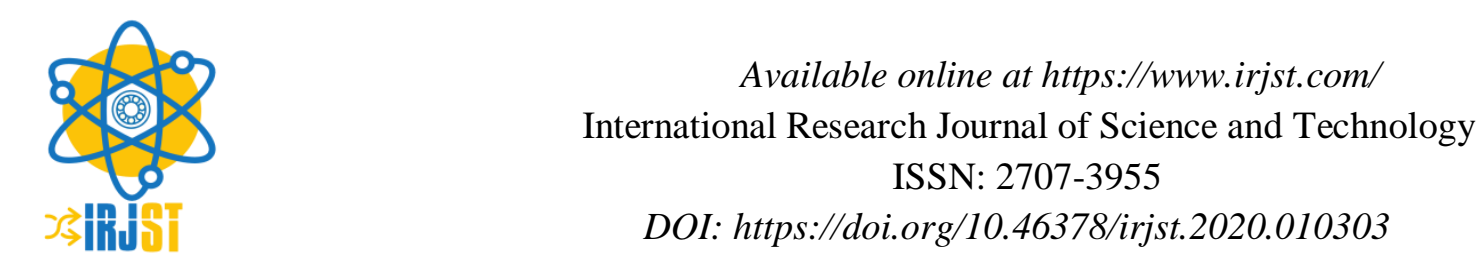

\title{
Performance Evaluation of Lead Acid Battery -Backup Power System of Solar Hybrid Power Plant.
}

\author{
Bayew Adera ${ }^{1}$ and Omprakash Sahu ${ }^{2}$ \\ ${ }^{1}$ Department of Chemical Engineering, KiOT, Wollo University, Ethiopia \\ ${ }^{2}$ Department of Chemical Engineering, UIE, Chandigarh University, India
}

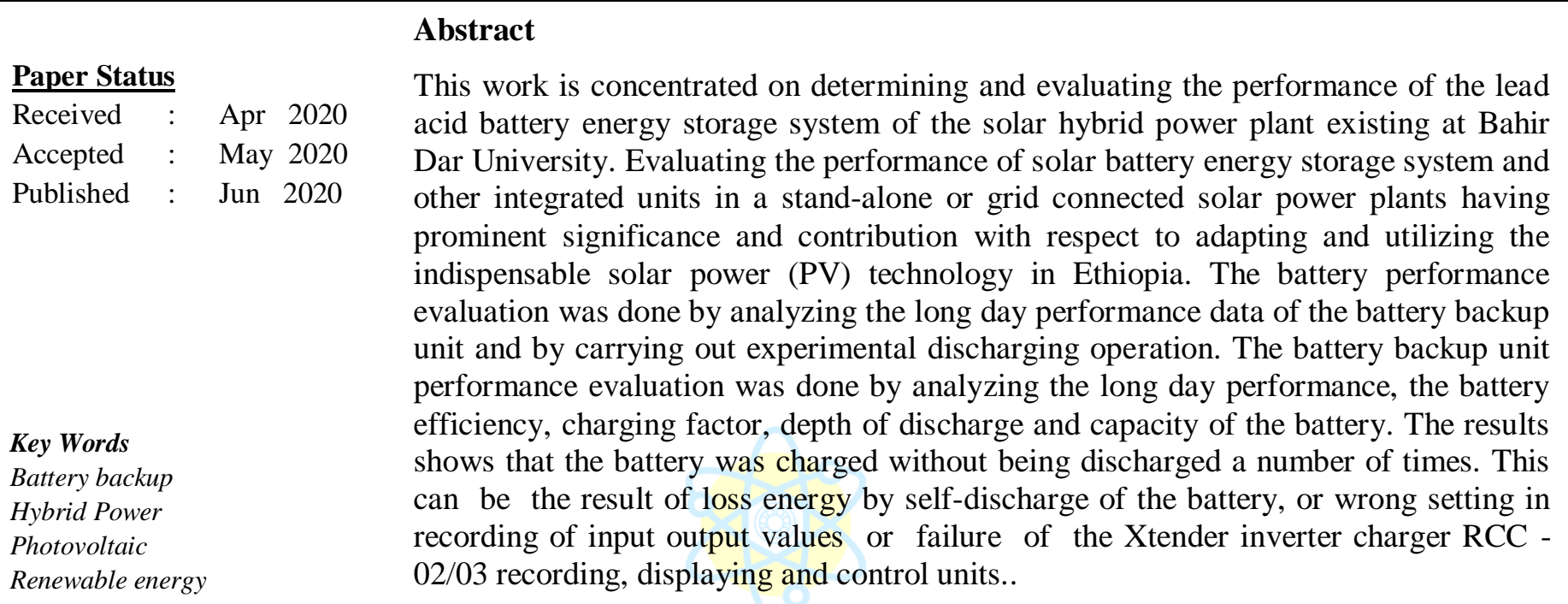

Copyright ( ) 2020: Bayew Adera, Omprakash Sahu. This is an open access distribution, and reproduction in any medium, provided Access article distributed under the Creative Commons Attribution License the original work is properly cited License, which permits unrestricted use.

Citation: Bayew Adera, Omprakash Sahu. "Performance Evaluation of Lead Acid Battery -Backup Power System of Solar Hybrid Power Plant.". International Research Journal of Science and Technology, 1 (3), 206-214, 2020.

\section{Introduction}

Mankind has consumed large quantities of fossil fuel in the last centuries for electric generations, transportation and other Purposes. As result, it is expected that the economical exploitable petroleum and natural gas reserve will be depleted and used up with the next 40 to 80 years as it is not renew able source of energy [1]. This has caused the price of energy resources to raise rapidly, environmental pollution and global warming. Renewable energy especially solar power is an indispensable part of the power supply in the future, worldwide [2].

\footnotetext{
* Corresponding Author: Omprakash Sahu

Department of Chemical Engineering, UIE, Chandigarh University, India

Email: ops0121@gmail.com
}

The purpose of using storage is to match the load profile with the solar production and it is claimed that with the storage, the utilities can enhance dispatch ability.

Battery energy storage systems have emerged as one of the most promising near-term storage technologies for power applications, offering a wide range of power system applications such as area regulation, spinning reserve, and power factor correction [3, 4]. The price of conventional energy sources in remote areas, such as candles, paraffin, gas, and coal is often more expensive than in urbanized areas due to the remoteness of the retailers. Moreover the cost per energy service, for lighting, is more expensive for a rural inhabitant than for their urban counter- parts that often have access to grid electricity [5].There are also other factors associated with conventional energy supply in remote areas, such as the, often long, transport required to obtain these energy supplies and the dangers in their use or storage [6]. To convert the 
electrical energy generated from PV system into chemical energy and store; supply electrical energy to the loads at the time of no power generation from PV system by reconverting the stored chemical energy into electrical energy $[7,8]$.

The battery accomplishes this task by virtue of its internally reversible electrochemical reaction that occurs at each cell of the battery at the time of its charging and discharging operation [9]. The most important feature of battery operation in $\mathrm{PV}$ technology is its cycling operation [10]. During the daily cycle, the battery is charged over the day and discharged by night time load and/or day time load, reduced power availability for grid system. Superimposed onto the daily cycle is the seasonal cycle, which is associated with periods of reduced radiation availability [11]. Appropriate battery storage system having maximum performance and minimum cost has significant contribution in minimizing the overall cost of the PV system [12].

The subject matter of this project is to evaluate the performance of lead acid battery used at Bahir Dar University, IOT campus; by experimentally discharging the battery for a number of days and obtaining the long term performance data registered by the system data logger unit and analyze both the experimental and long term performance data in order to evaluate and identify the battery charging and discharging performance and to indicate (select) the depth discharge that maximizes the life time of the battery and minimize the cost requirement associated with maintenance and replacement of new batteries. The main objective of this research work $t$ is to determine and evaluate the performance of the Lead Acid Battery energy storage system of the solar hybrid power plant at Bahir Dar University.

\section{Material and Methods}

Materials used: OPZS 800 lead acid battery (24 lead acid solar battery cells) as back power unit obtained from Bahir dar University hybrid solar power plant was used for the performance evaluation study. Total nine numbers of Lamps each with 500W obtained from local Electricity Board Ethiopia. To supply power from discharging battery (DC source) to AC lamps, battery inverter (bi directional converter, which converts $\mathrm{AC}$ to $\mathrm{DC}$ and/or $\mathrm{DC}$ to $\mathrm{AC}$ ); thick threephase cables and modify divider was made. To determine time of discharging, control and to record discharging parameters, Battery Status Processor (BSP), Extender Data Logger units and SD card along with the set up were used for this study. RCC-02/03 Control Centre with device configurations was used to measured operational values (current / voltage / power output etc).Experimental procedures are to evaluate the performance of the battery backup power system lamps each 500W as discharging load were used. The actual discharging performance values of the battery were analyzed using Xtender excels and mat lab script analysis tools [13].

The experimental procedures and set up are to examine the discharging performance of the backup system of the power plant experimentally, first the battery energy storage of the power plant ( 24 lead acid battery cells, OPzS 800 type, each with $2 \mathrm{~V}$ nominal voltage and $48 \mathrm{~V}$ ) was fully charged and made available in Fig.1.(Fig. 1a). Nine lamps each with 500W; equivalent to the $4.5 \mathrm{KW}$ AC load of power plant, was made available and arranged in a parallel connection in such a way that they can get power from the discharging battery( Fig. 1b). In order to supply power to the AC lamps only from the discharging battery the power supply transmission line to AC load (computer room) was reconnected to the equivalent AC lamps (load).The experiment was carried out at night to switch off power from PV2 (polycrystalline panels or modules) to AC lamps. Grid power to lamps was off from the main switch to supply power to the lamps only from the discharging battery [22]. The battery status processor and Extender Data Logger units were made ready and set immediately before discharging in order to register new discharging values on the SD card in the form of CSV files (Fig.1e). At 10:25 the first lamp is supplied power from the battery source and then the second lamp continues after two minute the rest continues with two minute interval (Fig.1d). The total lamps get power from the battery after the last lamp get power from the battery. The over lamp give light using the discharging battery, and the battery discharging was done until mid-night at which the data recorded by the data logger is saved on the SD card. Finally the power was manually off and the card was withdrawn and imported from Xtender Data Logger to computer for analysis (Fig. 1e) [14]. Software analysis of BSP data Logger: The data logger analyzes the long term data of power plant recorded at each minute interval of the day by the battery status processor and stored in SD card in the form of CSV files. In order to evaluate the performance of the battery backup system, the data logger file should have to be analyzed using appropriate software. The most reliable software to analyze this data logger file was extender excel script or extender mat lab script [15]. 

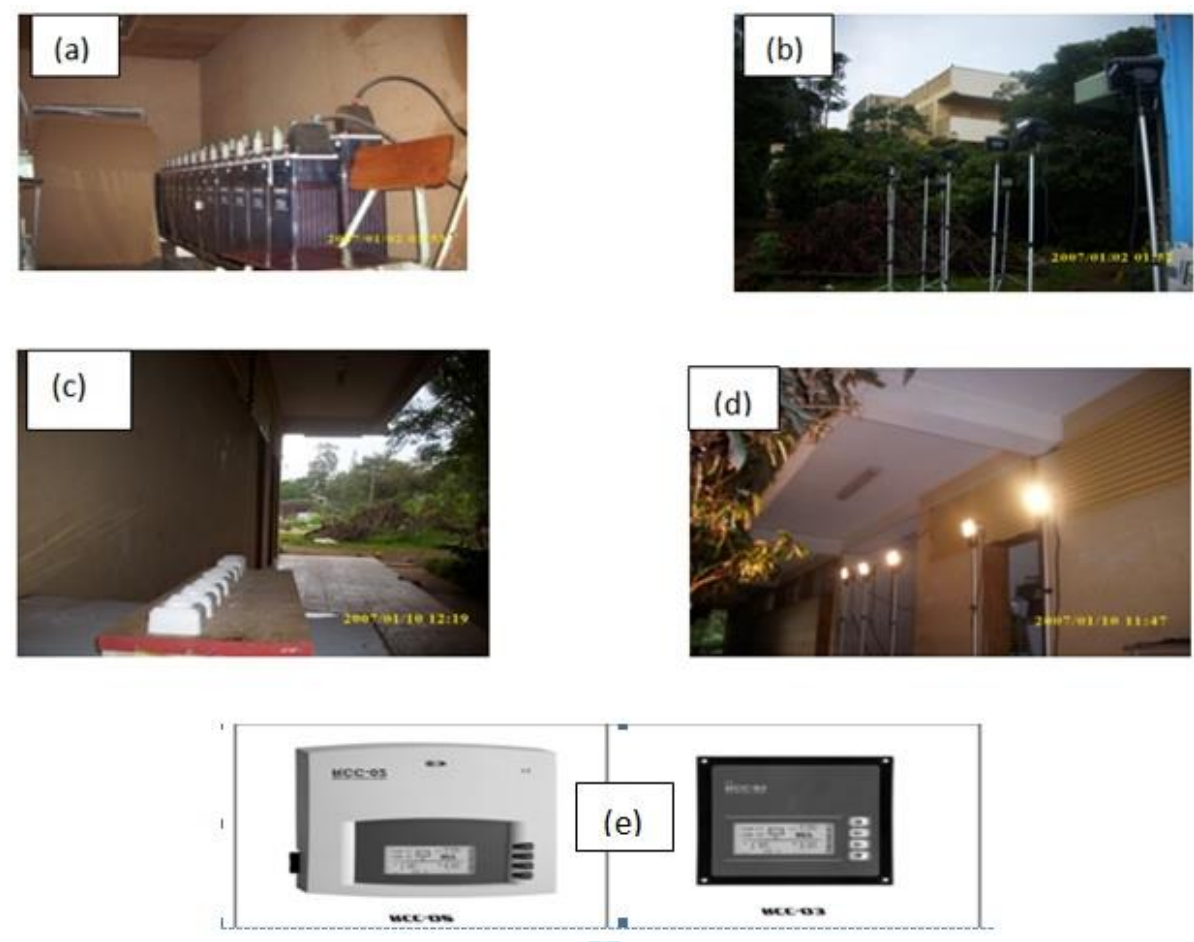

Fig.1: Set up of discharging the battery: a) 24 battery cells in series; b) lamp setup (AC load); c) Divider;

d) Lamp lighting by battery power and e) Battery status processor and data Logger unit and SD card

\subsection{Battery Charging and Discharging}

Extenders excel analysis procedures and descriptions: To evaluate the performance of the battery backup power system by analyzing the actual performance data of long durations SD card of the power plant that contains a number day's data in the form were taken. The year 2011 and 2012 CSV files of system, total of 300 day were obtained. The year 2011 and 2012 CSV files starting from 01/04/ 2011 to 31/12/ 2011 and starting from 01/01/2012 to 06/08/2012 LOG data CSV files were imported separately. The imported data logger LOG data of each day that has 1400 list of records were analyzed based on monthly and yearly using Extenders excel analysis tool. The overall performance of the battery of the year 2011and 2012 was determined both analytically and graphically using excels and mat lab respectively [16].

\section{Results and Discussion}

\subsection{Battery charging and discharging in 2011}

Ah discharge: The average discharge of the battery is used to determine and evaluate daily depth of discharge, battery efficiency and charge factor. The CSV file of August 16, 2012 was anal sized using
Xtender excel daily analysis tool. Experimental analysis result showed that the average battery discharge was -8.30Ah and the maximum and minimum battery discharge were $9.5 \mathrm{Ah}$ and $1.8 \mathrm{Ah}$ at 1240th and1100th minute of the day. The experimental battery discharging analysis result indicated that the total discharge obtained for total discharge duration of $6.58 \mathrm{hrs}$ was $305.3 \mathrm{Ah}$. The experimental battery discharging analysis further indicated that if the battery had been discharged at an average battery discharge of $-8.30 \mathrm{Ah}$ for 24 hours, according to the system design, total discharge of 1212Ah would have been obtained. The backup power system was designed and configured to deliver total of 3696 Ah discharge in a day (24hr discharge duration) at daily depth discharge of (DOD) of 50\% and optimum discharge voltage of 48V[22]. Extensive researchers showed that reliable energy from long lasting, safe and cost effective battery can be obtained when battery operates at optimum charge and discharge performance and condition. In addition they showed that for a specified battery operating condition the optimum battery charge and discharge values should lie in the standard charge factor range of 1.0 to 1.02 or battery discharging efficiency $98.6 \%$ 
to100\% [17]. Using the overall experimental battery discharging analysis result and using relation the average daily depth discharge (DOD) obtained experimentally was $16.4 \%$. The battery delivered only $32.79 \%$ of the design capacity, 3696 Ah.
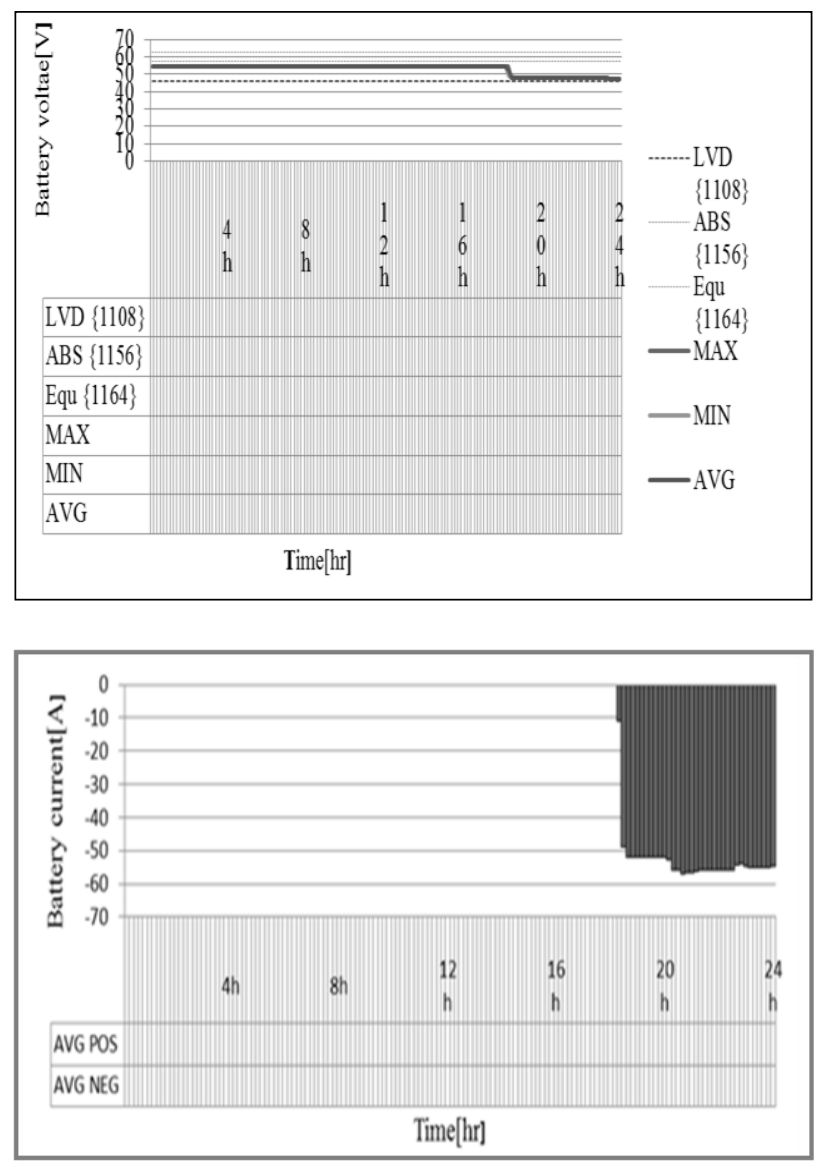

Fig.ure 2 : Experimental battery discharge current and voltage (a) Battery discharge voltage (b) Battery discharge current (DC current) August 16, 2012

Analysis of long term data of BSP The data logger record, store, and display long-term data of a power plant at each minute interval of the day by the battery status processor remote control center units (RCC02/03). Every day input output electrical data values of the power plant is recorded at each minute interval starting from the staring day first minute of mid night and saved at the last minute of staring day in SD card of the system in the form of CSV file format, (LG yy $\mathrm{mm}$ dd.CSV). One day Data Logger files has1440 records. To evaluate the efficiency of the battery backup system, two year CSV files were obtained from $\mathrm{SD}$ card of the system. These data which comprises of a total of 300 data Logger files were imported and analyzed independently [18].

Charging and discharging characteristics of year 2011: In year 2011 a total of 103 days ( total days of seven months of year 2011) data Logger CSV files were imported and generated on monthly and yearly basis using Xtender Microsoft excels analysis tool starting from LG 110430 to LG 111231 (from 1st April to 31th December 2011). From the yearly basis analysis the average charging and discharging current in [ADC] and plot of time [month] along with the data table was obtained. Battery average charging DC current is designated as positive, AVG POS and the average discharging DC current is designated as negative, AVG NEG.

Ah charge and discharge: the average Ah charge and discharge was used to determine and evaluate daily depth of discharge, battery efficiency and charge factor. The average Ah charge and discharge of year 2011 analysis showed that, the maximum battery average monthly Ah charge and discharge was 197.53 Ah and -98.2489Ah and seen on July 2011.
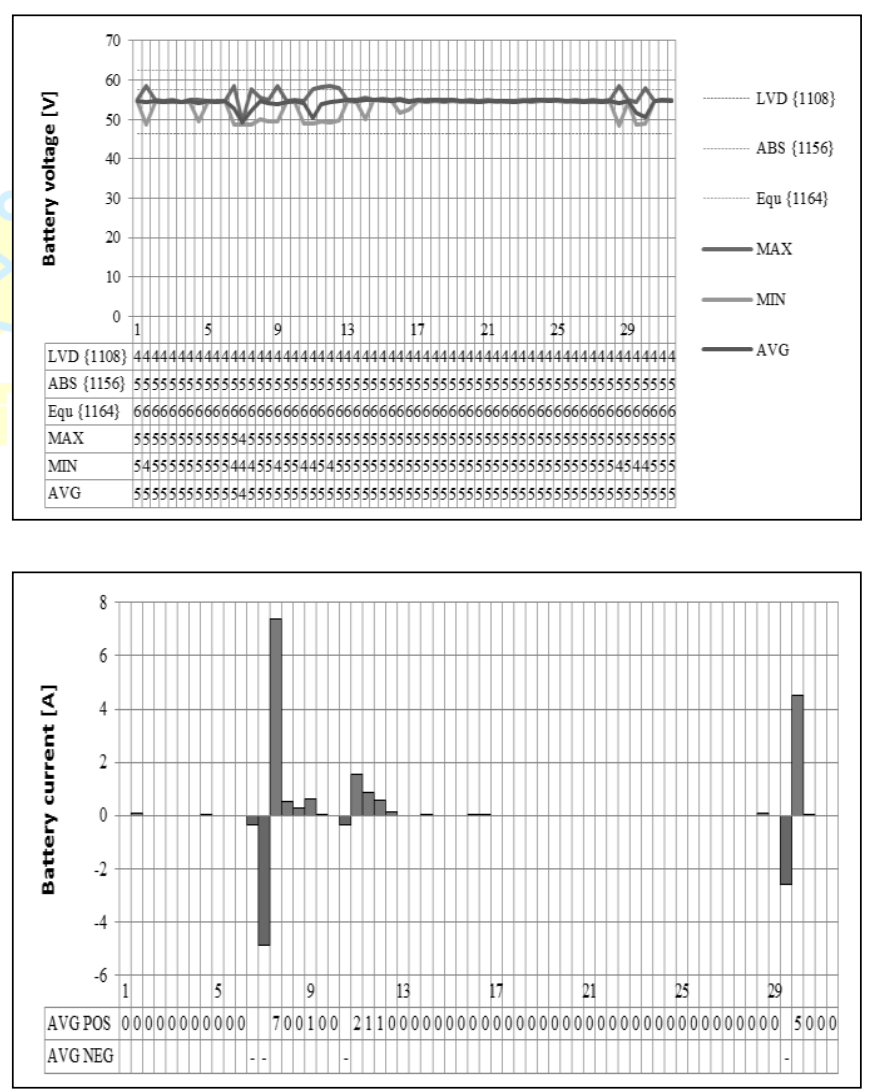

Figure.3: Battery maximum charging and discharging operating month (July 2011) (a) Battery average daily charging and discharging voltage (b) Battery average daily charging discharging current on July 2011

The year 2011 battery performance analysis result indicated that the minimum average charge and discharge as shown on table10 and 12 were $3.78 \mathrm{Ah}$ on November 2011 and 0 Ah on August 2011. 

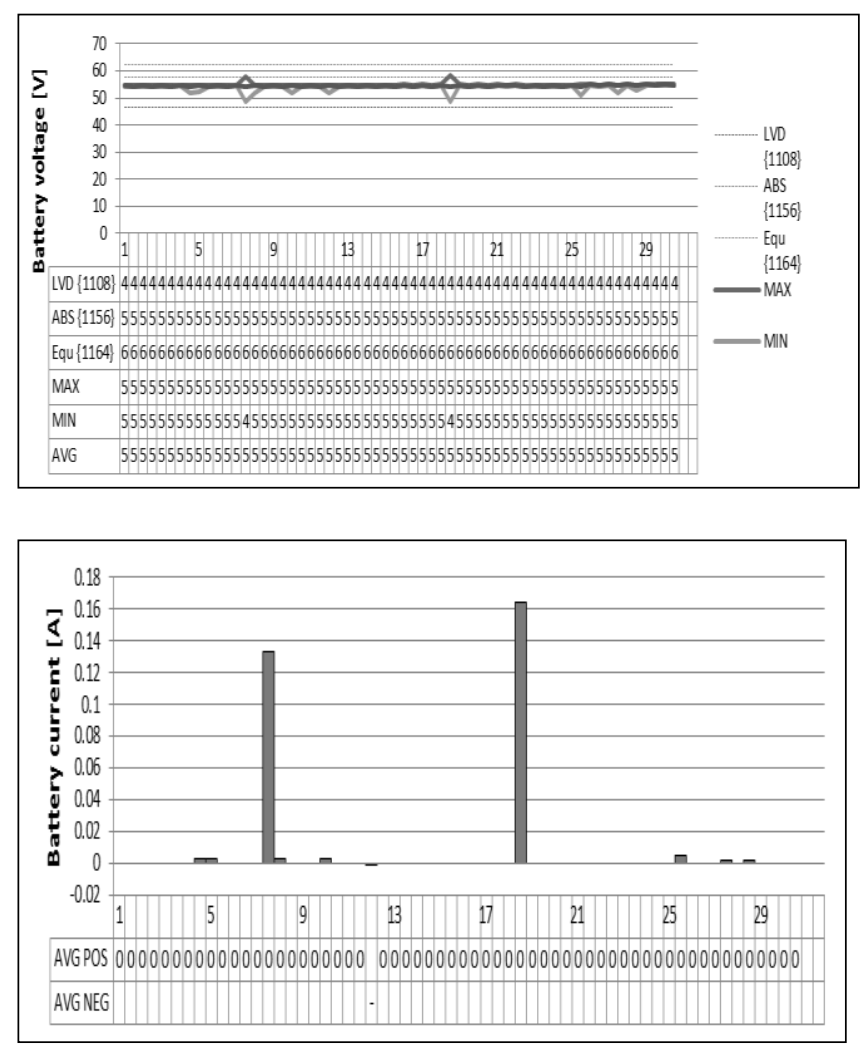

Figure.4: Battery minimum discharging operation month (a) Battery average daily discharging voltage (b) Battery daily average charging and discharging current on November 2011.
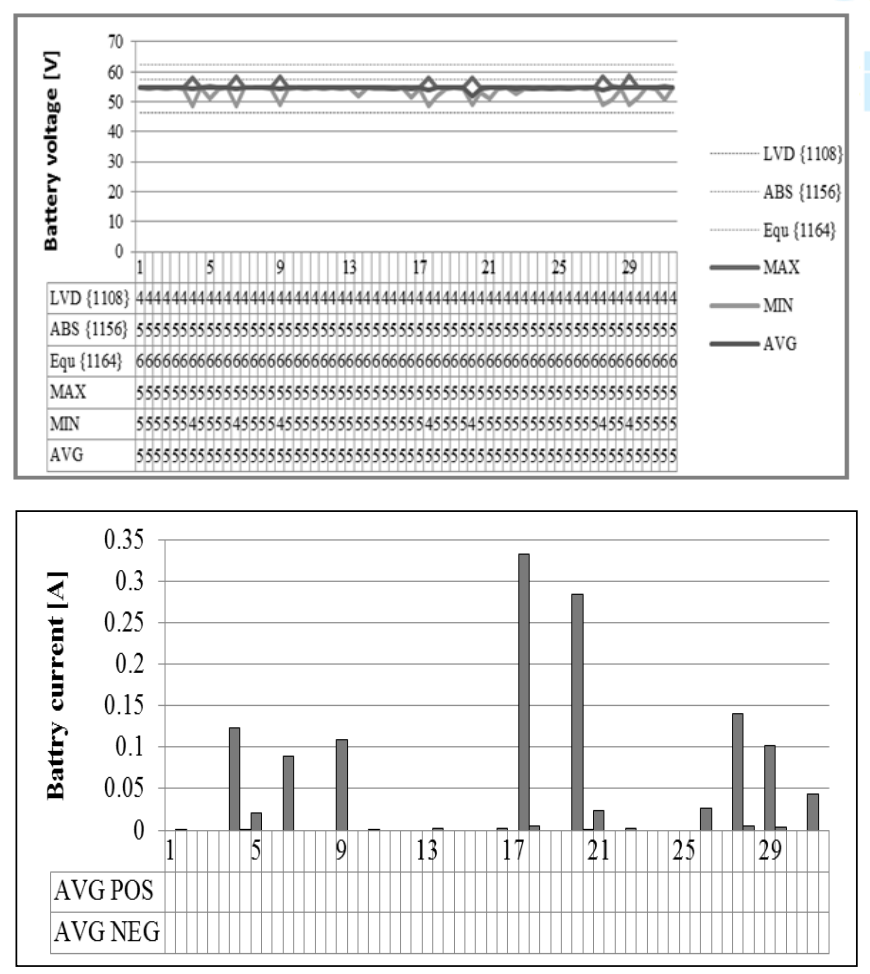

Fig.5: Battery minimum discharging operation month (a) Battery average daily charging and discharging voltage (b) Battery average daily charging discharging current on August 2011.
The overall 2011 analysis result showed that the average charge range was $3.78 \mathrm{Ah}$ to $197.53 \mathrm{Ah}$ and the average discharge range was $-0.016666 \mathrm{Ah}$ to 98.2489Ah.
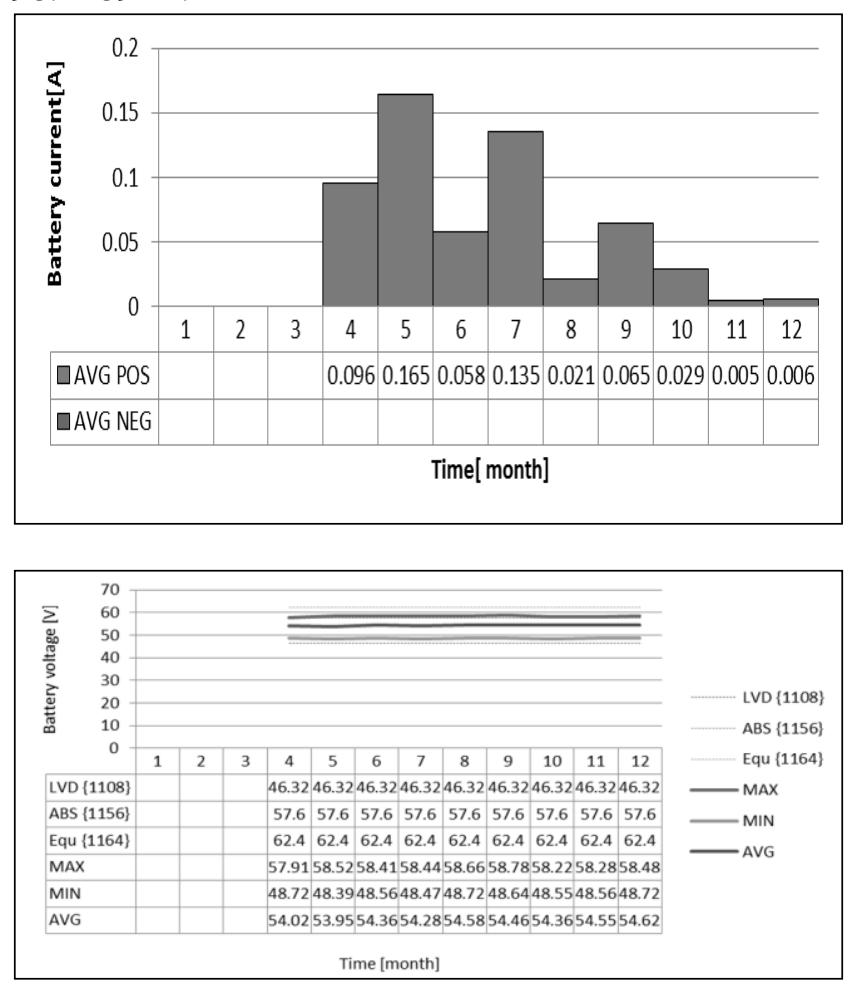

Fig.6: Battery average charging and discharging current and voltage (a) Battery average monthly charging and discharging current (b) Battery average monthly charging and discharging voltage in year 2011.

The overall 2011 analysis result also showed that the total charge and discharge were 100.655Ah and 49.133Ah. The charging and discharging performance determined using battery efficiency and charge factor relation was 0.48813 (average battery discharging efficiency $48.8 \%$ ) and the average charge factor was 2.05. Extensive researchers showed that the optimum battery discharging operation has a depth of discharge (DOD) in the range of $20-80 \%$ and also they explain that the optimum charging and discharging battery operation that protects the battery from either deep discharge or from over charge have charge factor, 1.0 to 1.2 [19]. The overall 2011 the analysis result showed that the charging and discharging performance of the battery was out of the standard reference values (discharging efficiency $48.8 \%$ and the charge factor 2.05). As shown from the year 2011 overall average battery charge and discharge analysis. It is also observed that the number of battery discharge cycles (level of usage) at each month or the total number of battery discharge cycles ( level of usage) throughout the year was significantly less than the associated recharge cycles [20]. Capacity and DOD the OPzS 800 lead acid battery: The type and size of battery selection depend on the installation design of the hybrid power 
plant. The vented stationary tubular solar OPzS800 lead acid was selected whose specifications, nominal capacity800Ah (800Ah) at nominal discharge duration $24 \mathrm{hr}$ (C24) maximum capacity $915 \mathrm{Ah}(915 \mathrm{Ah})$ at minimum discharge duration $10 \mathrm{hr}(\mathrm{C} 10)$ and 24 cells wired seriously each with $2 \mathrm{~V}$ nominal voltage that gives $48 \mathrm{~V}$ system $\mathrm{DC}$ voltage.

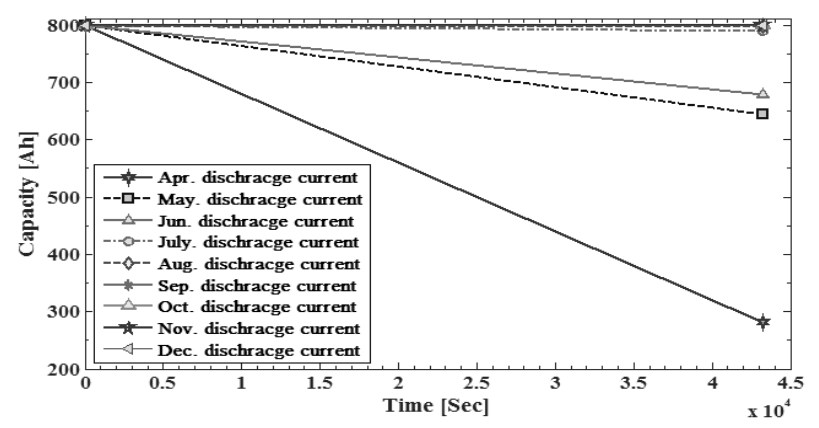

Figure 7: Battery capacity variations for different average monthly DOD, Year 2011.

As shown from Fig. 7, for different average monthly DOD of battery, the available average capacity of left after discharging the battery at different average monthly DOD with respect to the initial fully charged battery nominal capacity 800Ah (nominal capacity when the battery was new) was obtained. From the overall 2011 analysis result and counting showed that the average charge/discharge cycle is min. Average monthly DOD profiles indicated that the available average capacity decreases as DOD increases and the available average capacity increases as DOD decreases Life cycle obtained by counting the number of cycles for a typical one week PV power dispatch ability was . Life of battery for different and an average DOD in 2011 levels is shown table 15 . The battery capacity should be decreased over time [21]. Analysis result showed that the average the capacity was made to decrease with different slope depending on the DOD. This indicated that the aging to the battery due to time was implemented, which is similar to literature values [22].

\subsection{Battery Charging And Discharging Analysis Year 2012}

Ah charge and discharge: From the monthly basis analysis (from1st January to 31th July 2012) as shown (table 34-40 on appendix) the average Ah charge and discharge of each month was calculated. In the year 2012 battery performance analysis it was observed that the maximum battery average charge and discharge (Table 17) was $918.98 \mathrm{Ah}$ and $-518.92 \mathrm{Ah}$ and was seen in January 2012. And the analysis has also shown (Table19) that the minimum battery average charge and discharge was 6.13 Ah and $0 \mathrm{Ah}$ and seen in April 2012.
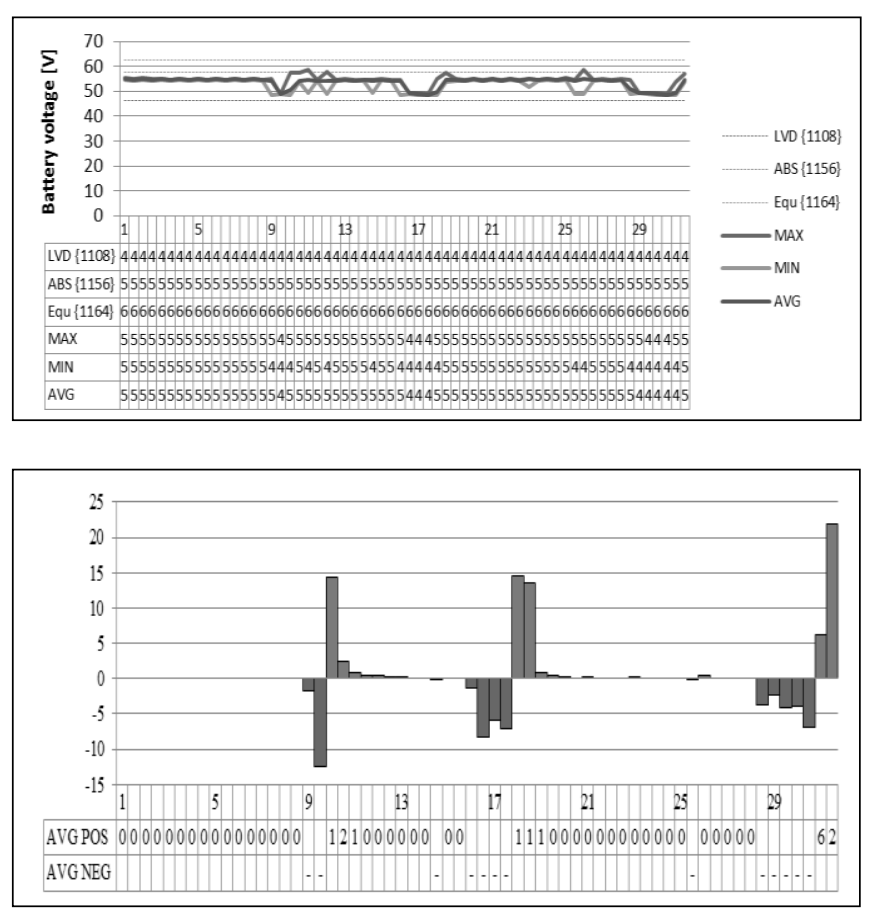

Figure 8: Battery maximum charging and discharging operating month (a) Battery average daily charging and discharging voltage (b) Battery average daily charging discharging current on January 2012.
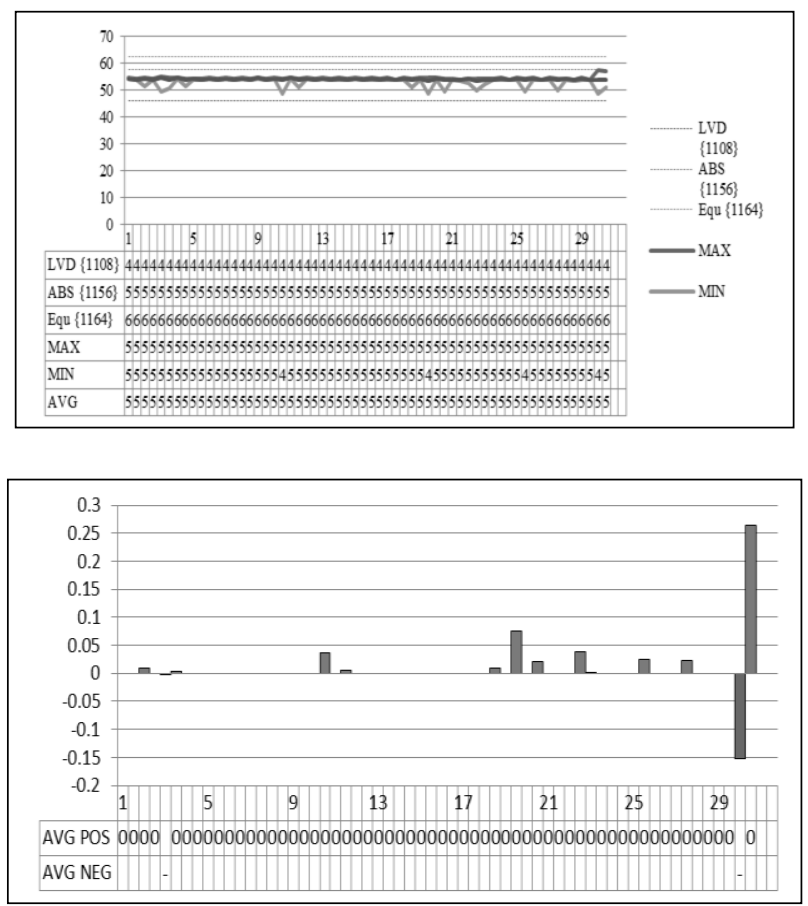

Figure 9: Battery minimum charging and discharging operating month (a) Battery average daily charging and discharging voltage (b) Battery average monthly charging and discharging current in 2012. 



Figure 10: Battery maximum charging and discharging operating month (a) Battery average charging and discharging voltage (b) Battery average charging and discharging current (January 2012).

The overall 2012 analysis result showed that the average charge range was 6.13 Ah to $918.98 \mathrm{Ah}$ and the average discharge range was 0 Ah to $-518.92 \mathrm{Ah}$.
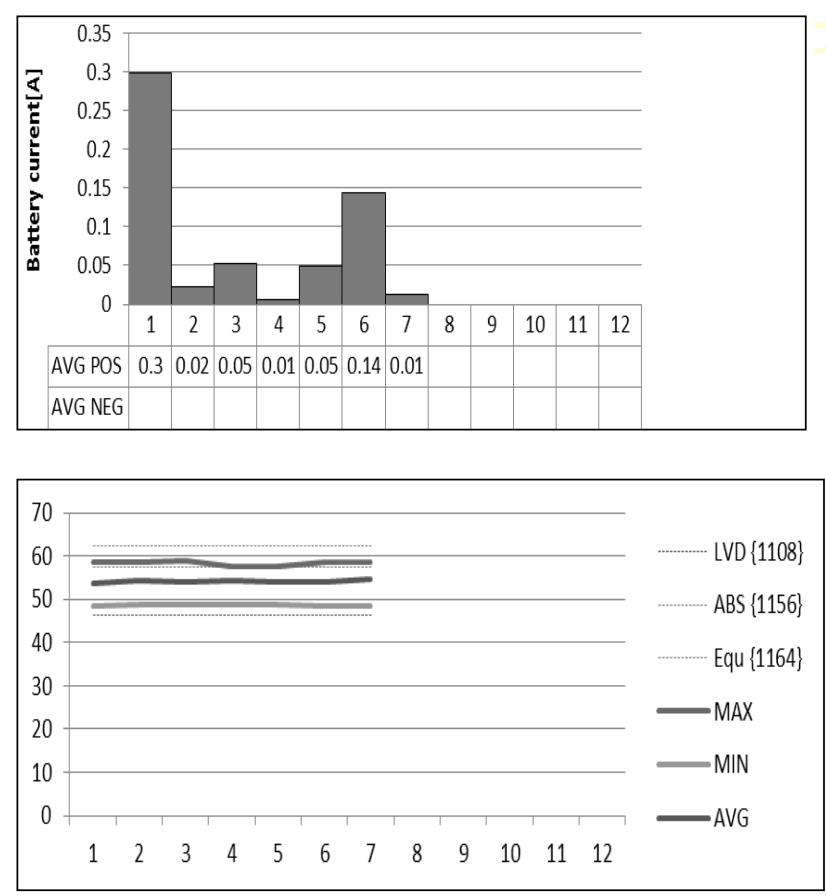

Figure 11: Battery average charging and discharging current and voltage (a) Battery average monthly charging and discharging current in year 2012 (b) Battery average monthly charging and discharging voltage in year 2012 .
As the year 2012 analysis result that indicated, the average battery charge and discharge (average of maximum and minimum) was 462.555 Ah and 259.46Ah. The year 2012 analysis has also shown that the total number of discharge cycles (level of usage) of the seven (7) months of the battery in the year 2012 was 24 as compared to the 134 total number charge cycles within the same operation period of battery in the year 2012.

In addition as shown from year 2012 analysis result above, the average monthly charge and discharge energy into and out of the battery was 202.61 Ah and 115.49 Ah for the total number charge and discharge cycles of 134 and 24 respectively .Using these overall result and the relation (4.4), the total charge and discharge energy into and out of the battery in the year 2012 was 27, 149.74 Ah and 2,771.76 -Ah. The overall battery performance problem in the year 2012 like the year 2011 battery performance problem indicated that either the battery had been discharged by itself (a condition of self-discharge problem). Or the input output recorded data values of the system were wrong (the electrical and mechanical or both problems controller sensors switches of BSP RCC02/03 the system) [23].

Capacity and DOD the OPzS 800 lead acid battery: To characterize and determine the performance of battery for 12 hour discharge duration DOD was calculated as shown in table 6. And the nominal capacity in [Ah] versus average monthly DOD (average of the seven different months in 2012) was plotted. Extensive researchers showed that the capacity in the battery model is made to decrease with different slope depending on the DOD to get an approximate aging implementation to the model [9].

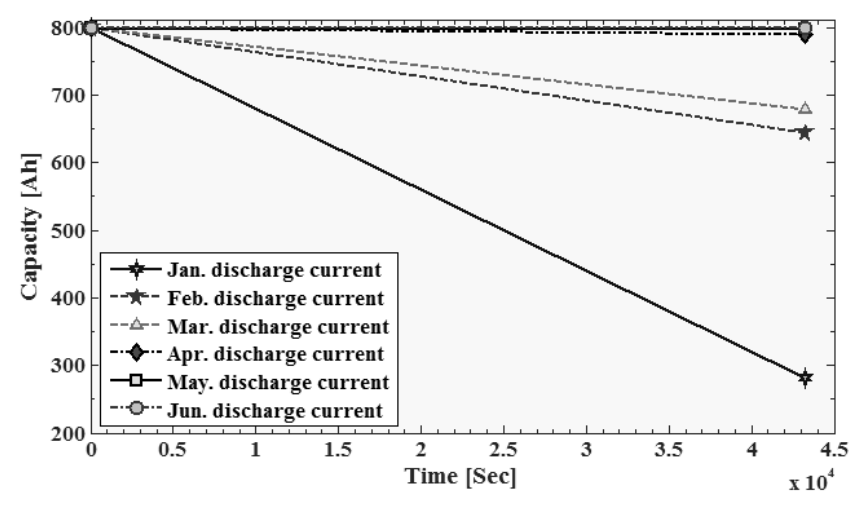

Figure 12: Battery capacity variations for different average DOD

From the overall 2012 analysis result average monthly DOD profiles indicated that the available average capacity decreases as DOD increases and the available average capacity increases as DOD decreases Analysis result also showed that the average the capacity was 
made to decrease with different slope depending on the DOD. This indicated that the aging to the battery due to time was implemented, which is similar to literature values the faster decrease of battery capacitance with higher discharge current is seen in Fig.12.

\section{Conclusion}

The results of battery discharging experiment showed that the daily discharge was found to be $16.4 \%$ as well battery delivered only $32.79 \%$ of the pre-set value that was configured and designed at the time of power plant installation for a day to supply total discharge of $3696 \mathrm{Ah}$ at 50\% DOD. The year of 2011 overall battery charging and discharging performance analysis result showed that the battery charge factor and efficiency were found to be 2.05 and $48.8 \%$ respectively. In year 2012 overall battery charging and discharging performance analysis result showed that the battery charge factor and efficiency were found to be 9.79 and $10.21 \%$, which is out of the range of literature values. It was found that in year 2011 and year 2012 overall battery charging and discharging performance analysis result shows battery was charged without being discharged a number of times. Thus from the results of both long day (two year) performance and experimental data analysis, it can be concluding that the battery was charged without being discharged a number of times and in general the backup (island) system was not working properly. This can be of loss energy by self-discharge of the battery, wrong setting or recording of input output values or failure of Xtender inverter charger RCC -02/03 recording, displaying and control units. As the performance of battery backup system of integrated hybrid solar power plants depends not only on charging discharging of the battery but also it depends on the performance of each of the sub units of the power plant. Therefore to adapt and utilize the indispensable solar power at maximum performance further research needs to be done. Especially to identify the causes of the problem of the backup system of the hybrid power plant at campus further study and investigation on each unit of the power plant must be done.

\section{References}

[1]. Dincer, I., 2000. Renewable energy and sustainable development: a crucial review. Renewable and sustainable energy reviews, 4(2), pp.157-175.
[2]. Ellabban, O., Abu-Rub, H. and Blaabjerg, F., 2014. Renewable energy resources: Current status, future prospects and their enabling technology. Renewable and Sustainable Energy Reviews, 39, pp.748-764.

[3]. Kyriakopoulos, G.L. and Arabatzis, G., 2016. Electrical energy storage systems in electricity generation: Energy policies, innovative technologies, and regulatory regimes. Renewable and Sustainable Energy Reviews, 56, pp.10441067.

[4]. Faisal, M., Hannan, M.A., Ker, P.J., Hussain, A., Mansor, M.B. and Blaabjerg, F., 2018. Review of energy storage system technologies in microgrid applications: Issues and challenges. IEEE Access, 6, pp.35143-35164.

[5]. Opiyo, N., 2016. A survey informed PV-based cost-effective electrification options for rural subSaharan Africa. Energy Policy, 91, pp.1-11.

[6]. Bensch, G., Grimm, M., Huppertz, M., Langbein, J. and Peters, J., 2018. Are promotion programs needed to establish off-grid solar energy markets? Evidence from rural Burkina Faso. Renewable and Sustainable Energy Reviews, 90, pp.10601068 .

[7]. Burnham, A., Dufek, E.J., Stephens, T., Francfort, J., Michelbacher, C., Carlson, R.B., Zhang, J., Vijayagopal, R., Dias, F., Mohanpurkar, M. and Scoffield, D., 2017. Enabling fast charging-Infrastructure and economic considerations. Journal of Power Sources, 367, pp.237-249.

[8]. Valer, L.R., Manito, A.R., Ribeiro, T.B.S., Zilles, R. and Pinho, J.T., 2017. Issues in PV systems applied to rural electrification in Brazil. Renewable and Sustainable Energy Reviews, 78, pp.1033-1043.

[9]. Wang, Y., Leung, D.Y., Xuan, J. and Wang, H., 2016. A review on unitized regenerative fuel cell technologies, part-A: Unitized regenerative proton exchange membrane fuel cells. Renewable and Sustainable Energy Reviews, 65, pp.961-977.

[10]. Batchelor, S., Brown, E., Leary, J., Scott, N., Alsop, A. and Leach, M., 2018. Solar electric cooking in Africa: Where will the transition happen first?. Energy research \& social science, 40, pp.257-272.

[11]. Khalilpour, R. and Vassallo, A., 2016. Planning and operation scheduling of PV-battery systems: A novel methodology. Renewable and Sustainable Energy Reviews, 53, pp.194-208.

[12]. Grzesiak, W., Mackow, P., Maj, T., Polak, A., Klugmann-Radziemska, E., Zawora, S., 
Drabczyk, K., Gulkowski, S. and Grzesiak, P., 2016. Innovative system for energy collection and management integrated within a photovoltaic module. Solar Energy, 132, pp.442-452.

[13]. Luo, X., Wang, J., Dooner, M. and Clarke, J., 2015. Overview of current development in electrical energy storage technologies and the application potential in power system operation. Applied energy, 137, pp.511-536.

[14]. Zubi, G., Dufo-López, R., Pasaoglu, G. and Pardo, N., 2016. Techno-economic assessment of an off-grid PV system for developing regions to provide electricity for basic domestic needs: A 2020-2040 scenario. Applied energy, 176, pp.309-319.

[15]. Diouf, B. and Pode, R., 2015. Potential of lithium-ion batteries in renewable energy. Renewable Energy, 76, pp.375-380.

[16]. Aneke, M. and Wang, M., 2016. Energy storage technologies and real life applications-A state of the art review. Applied Energy, 179, pp.350-377.

[17]. Fernández, I.J., Calvillo, C.F., Sánchez-Miralles, A. and Boal, J., 2013. Capacity fade and aging models for electric batteries and optimal charging strategy for electric vehicles. Energy, 60, pp.3543.

[18]. Ahmadi, L., Fowler, M., Young, S.B., Fraser, R.A., Gaffney, B. and Walker, S.B., 2014. Energy efficiency of Li-ion battery packs re-used in stationary power applications. Sustainable Energy Technologies and Assessments, 8, pp.9-17.

[19]. Luthander, R., Widén, J., Nilsson, D. and Palm, J., 2015. Photovoltaic self-consumption in buildings: A review. Applied energy, 142, pp.8094.

[20]. Abed, K., Bahgat, A., Badr, M., El-Bayoumi, M. and Ragheb, A., 2016. Experimental results of computer monitoring of PV-based energy system. In Renewable Energy in the Service of Mankind Vol II (pp. 415-427). Springer, Cham.

[21]. Raja, J Jain, N.Christober, C., $\quad$ Rajan,A., 2019. Grid connected mega-watt range solar power plant in India: experimental measurement \& performance analysis. International Journal of Applied Power Engineering 8(1); 22-34.

[22]. Mohamed, T.S.,Mohammed, A., Abdel-Rahim, 2019 Terminal voltage and power regulation using vehicle-to-grid (V2G) schemes integrated to smart interconnected power system. International Journal of Applied Power Engineering 8(1); 61-68.

[23]. Balamurugan, C.R., 2018. Three Area Power System Load Frequency Control Using Fuzzy
Logic Controller. International Journal of Applied Power Engineering 7(1); 18-26. 